\title{
Effect of Utility Voltage Distortion on the Performance of Different Control Strategies for Shunt Active Power Filter
}

\author{
Ahmed M. A. Soliman, Salah K. EL-Sayed, and M. A. Mehanna
}

\begin{abstract}
The widespread use of power electronics in industrial, commercial and even residential electrical equipment like non-linear loads causes deterioration of the quality of the electric power supply with distortion of the supply voltage and in order to mitigate this quality the shunt active power filter (SAPF) is the suitable and effective solution for harmonic elimination and reactive power compensation and lead to power quality (PQ) improvement, therefor an effective and accurate current control technique is needed in order for a SAPF where control algorithm is the heart for SAPF to perform this function and its dynamic performance is mainly depends on these control strategy. This paper proposes three different current control strategies (CCS) based on instantaneous power theory and generalized Fryze theory which used for the generation or extraction of the accurate reference current signals which comparing with the actual signals through hysteresis current technique (HCT) to produce suitable gating signals for SAPF and discusses the performance for these controllers when the supply bus voltage is distorted with scope on the efficient control algorithm. Matlab / Simulink simulation results are presented to validate the control strategy and demonstrate the effectiveness of SAPF to provide mitigation of power quality problems for non-linear load to reach an acceptable value comply with recommended standards.
\end{abstract}

Index Terms-Shunt Active Power Filter (SAPF); Power Quality (PQ); Current Control Strategy (CCS); Hysteresis Current Control Technique (HCCT).

\section{INTRODUCTION}

One of the serious problems in electrical systems in recent years is the increasing number of power electronic equipment in power system including renewable power generations which lead to cause of power quality (PQ) problems for the operation of power system devises, where Power quality (PQ) covers all aspects of power system engineering from transmission and distribution level analyses to end-user problems. Therefore, electric power quality has become a serious concern for both utilities and end users [1].

The power quality (PQ) at distribution level, broadly refers to maintaining a near sinusoidal power distribution bus voltage at a rated magnitude and frequency, but one of the major issues that cause power quality problem is namely

Published on August, 31, 2017

A. M. A. Soliman is with Department of Electrical Power and Machines, Faculty of Engineering, Al-Azhar University, Egypt (e-mail: eng_ahmed1020@yahoo.com).

S. K. EL-Sayed is with Department of Electrical Power and Machines, Faculty of Engineering, Al-Azhar University, Egypt (e-mail: salah_kamal1982@yahoo.com ).

M. A. Mehanna is with Department of Electrical Power and Machines, Faculty of Engineering, Al-Azhar University, Egypt (e-mail mehanna2002@hotmail.com). harmonic distortion for voltage or current waveforms, the power electronic converters inject high power nonsinusoidal currents (i.e., harmonic) currents into the AC utility grid and the harmonics injected into the power system cause line voltage distortions at the Point of Common Coupling (PCC) where the linear and nonlinear loads are connected as shown in Fig. 1.

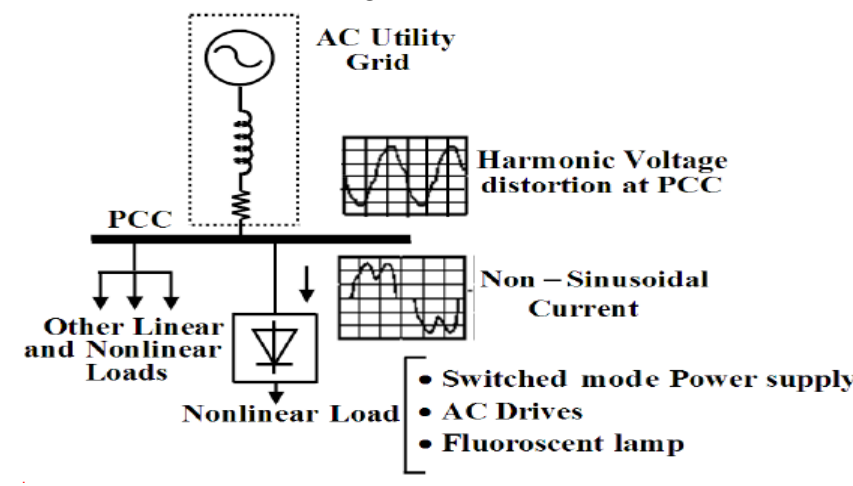

Fig.1. Harmonics distortion at Point of Common Coupling (PCC) [1].

The rapid development in the efficiency of the power electronic technology which offer many economical and reliable solutions to provides efficiency enhancement in the control and management for electrical energy utilization, therefore this technology leads to an expansion and proliferation for the using of modern power electronic equipment in a wide range of applications in distribution networks, particularly in domestic and industrial applications ,but those devices introduce a nonlinear operational characteristics because of the current vary disproportionately with the applied voltage, therefore the connection of the electrical network to these nonlinear loads cause the appearance of current and voltage harmonics and lower power factor $(\mathrm{PF})$, where current become nonsinusoidal and cause injection of harmonics and reactive power in the distribution system which leads to poor power system quality [1]-[3].

Also sources of harmonics in power systems are mainly obtained from three major areas as detailed and shown in Fig. 2, [1]:

- Fast switching of power electronic devices

- The conventional sources such as electrical rotating machines and Transformers

- The modern electronic equipment 


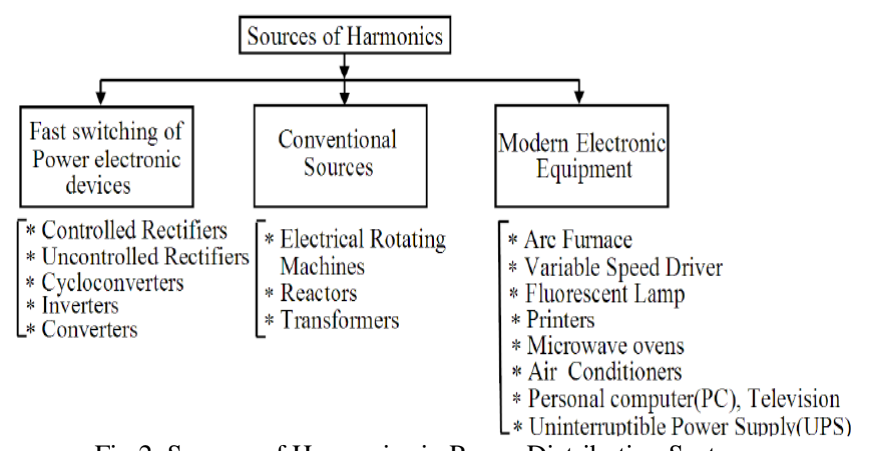

Fig.2. Sources of Harmonics in Power Distribution Systems.

The harmonic pollution due to presence of these harmonics in distribution system leads to additional losses in distribution system devices, low energy efficiency, harmonic resonances in the utility, incorrect operation or malfunction of harmonic sensitive loads, and interference with power equipment and communication networks, and also causes more undesirable effects such as improper operation of protection relays and circuit breakers which cause tripping of circuit breakers due to overload, overheating of distribution transformers, neutral heating due to triple $\mathrm{n}$ harmonics, etc. finally Lack of standard quality power due to presence of harmonics and reactive power can cause damage of equipment or even be harmful to human health resulting in loss of production and also has harmful effect and impacts leads to poor power factor and penetration of system power quality, Therefore in the recent years, focus has been given on improving "Electrical Power Quality" (EPQ) [3]-[5].

In order to mitigate the permanent power quality problem, there are techniques for reducing or eliminating harmonics from power systems by putting harmonic filters close to the current injection source where harmonic filters are designed to reduce the impacts of harmonic penetration when harmonic content has been exceeded in power distribution system, Hence, the Shunt Active power filters (SAPFs) are introduces to overcome these problems and have functions making it broadly utilized in active filtering applications for current harmonic reduction and power factor improvement, where active filters can suppress not only the supply current harmonics, but also the reactive currents and its performance is free and independent of the power distribution system properties, therefore SAPF become an effective and powerful solutions for many power quality problems [6].

The configuration of the shunt active filter is classified into two main parts consists of active filter controller, and power converter as shown in Fig. 3, where controller is responsible for determining the instantaneous compensating reference current, which is continually passed to the power converter which responsible for synthesizing the compensating current that should be drawn from the power system by utilizing an adequate modulation method [7].

From the point of view of practical applicability, active filtering can be of two types: partial filtering and total filtering. In the partial filtering case, the supply phase currents are balanced and sinusoidal or they have the same shapes as the voltages. In the total filtering case, the supply currents are balanced and sinusoidal or have the same shapes and zero crossing as the voltages. On the other hand, if the current is sinusoidal, the goal of filtering is "zero distortion factors" and if the current has the same shapes and zero crossing as the voltage, the goal of filtering is "unity power factor". So, the desired current can be the sum of the active and reactive components in the partial filtering case and the active component in the total filtering case [8].

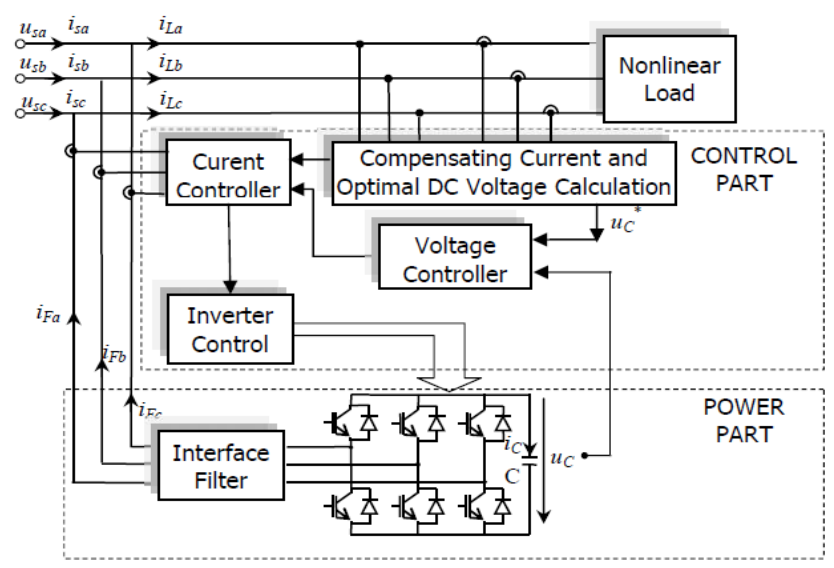

Fig.3. Configurations of the shunt active filter.

SAPF appear to be a viable solution for controlling harmonics associated problems and is implemented to draw/supply a compensated current from/to the utility and acting as an ideal current source injecting the proper nonsinusoidal harmonic components with the same amplitude but shifted or opposite in phase with the load harmonic current as well as absorbing or generating reactive power there by eliminating the unwanted harmonics and compensate for reactive power of the connected load and finally a result, the SAPF cancels out the load harmonic currents and leaves the fundamental current component to be provided by the power system and improve the poor system power factor (PF) and the supply currents becomes "clean" sinusoidal, free from harmonics and in phase with the distribution voltage source as shown in the Fig.4. Furthermore SAPF can keep the power system balanced under the condition of the unbalanced and the nonlinear loads [2],[4],[6].

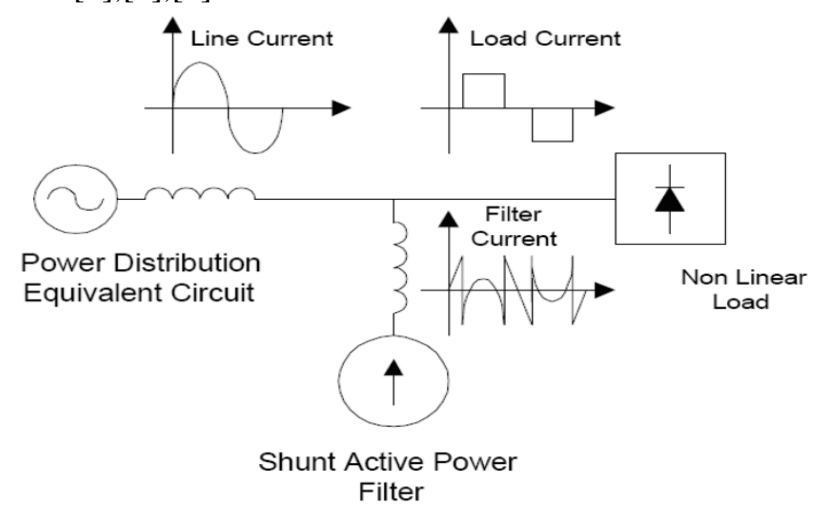

Fig.4. Compensating principle of Shunt Active Power Filter (SAPF).

\section{CONTROL STRATEGIES}

The control strategy of the SAPF can be implemented in two steps, where the first step is the extraction of compensating signals from the distorted signals represented by the reference current extraction method and the second step is represented by the current control technique based on hysteresis strategy which used for the generation of the appropriate firing signals to control the switching devices 
for SAPF based on the estimated reference signal [6].

This paper focus on the control algorithms which applied for extraction of the reference current signals based on the integration of four different control strategies which implemented as:

- Constant Instantaneous Power Control Strategy

- Sinusoidal Source Current Control Strategy

- Generalized Fryze Current Control Strategy

- $\quad$ Sinusoidal Fryze Current Control Strategy

Under sinusoidal, balanced system voltages, the three control strategies can produce approximately the same results. However, under non sinusoidal and/or unbalanced system voltages, each control strategy guarantees its respective compensation characteristic. Hence, the resultant compensated source currents are different [9].

\section{A. Constant Instantaneous Power Control Strategy}

The instantaneous active and reactive power theory, known as (p-q) theory, has been developed for three-phase three wire systems with balanced and sinusoidal source voltage. The compensation target is assumed to get a constant instantaneous source power [7].

The main advantages of this theory are the simplicity of its calculations, since only algebraic operations are required based on the instantaneous values in three-phase power systems for separation of some power components in their mean and alternating values from instantaneous active and reactive powers components based on an algebraic transformation (Clarke transformation) [7].

The (p-q) scheme with control block diagram shown in Fig. 5 is most widely used because it valid for steady-state or transitory operations and also provide fast dynamic response but it have some disadvantages, where it need more calculations and using low-pass filters to separate the instantaneous real and imaginary powers into average and oscillating parts, which introduces time delays that degenerate the active filter dynamic performance and it gives inaccurate results under distorted and/or asymmetrical source voltage conditions, where under this condition it is impossible to implement a shunt active filter that satisfies simultaneously[4],[9],[10]:

i) constant instantaneous real power drained from the network;

ii) sinusoidal compensated current; and

iii) Proportionality between the system voltage and the compensated current.

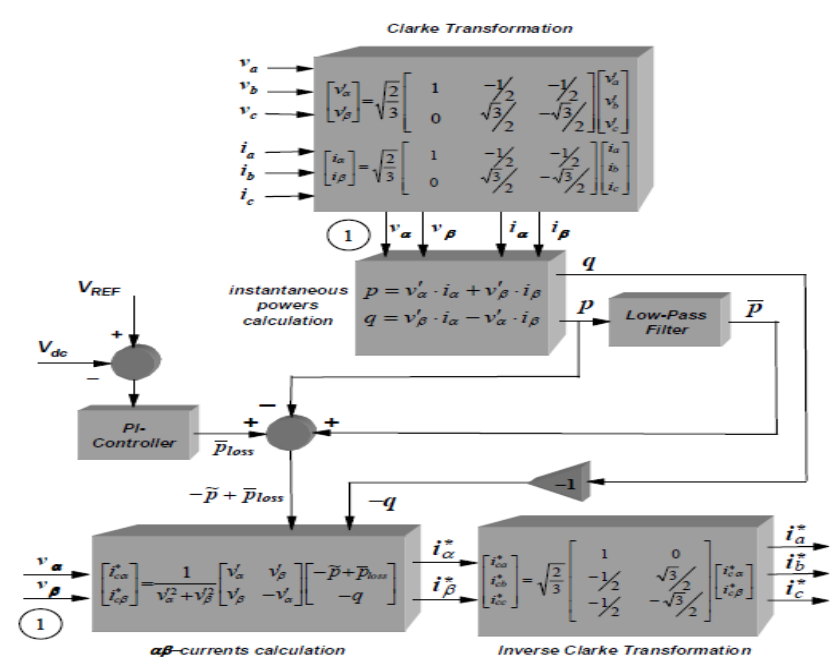

Fig.5. Control block diagram for constant instantaneous power control strategy.

\section{B. Sinusoidal Source Current Control Strategy}

In this control method the SAPF force the compensated current to be sinusoidal and cannot achieve both conditions to have sinusoidal and balanced current so to get constant power drawn from the utility it supposed to use the instantaneous power control strategy and also to get a sinusoidal compensated source current it supposed to use the sinusoidal current control strategy [12] - [13]. Based on this control strategy the SAPF should compensate all harmonics that are present in the current, but where the supply voltage mostly has positive sequence present in it beside may consists of negative sequence as well as zero sequence harmonics, therefore the positive sequence detector is being required in the filter to extract the amplitude, phase angle and frequency of the fundamental positive-sequence voltage $\left(\mathrm{V}_{+1}\right)$ and gives it in the form of instantaneous values. Therefore, the main difference between this control algorithm and the original (p-q) one, is the addition of the positive-sequence voltage detector which basically necessary and based on dual p-q control theory depending on an important part of the PLL (Phase Locked Loop) circuit, the control block diagrams for overall control algorithm, positive sequence voltage detector and PLL circuit are detailed in the Fig. 6,7, and 8, [9],[13],[14].

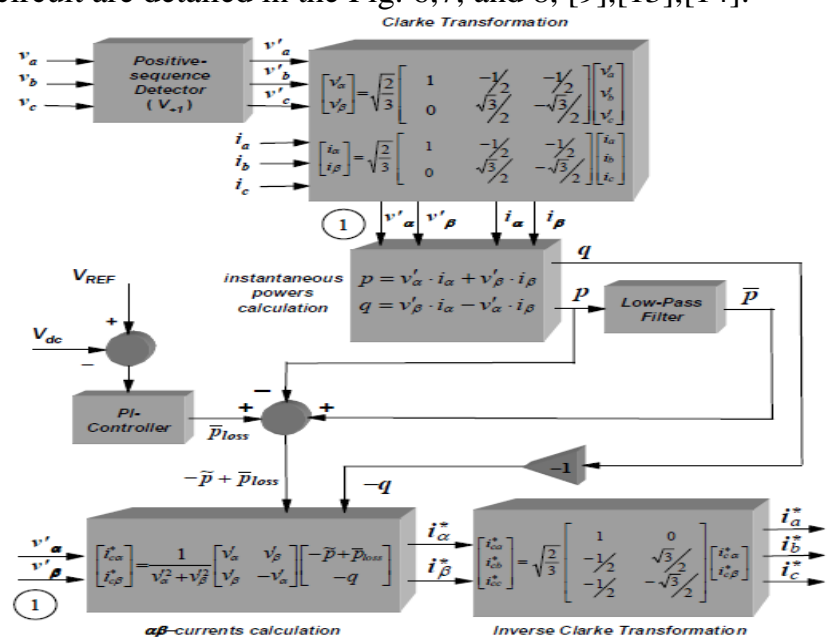

Fig.6. Control block diagram for Sinusoidal Source Current Control Strategy. 


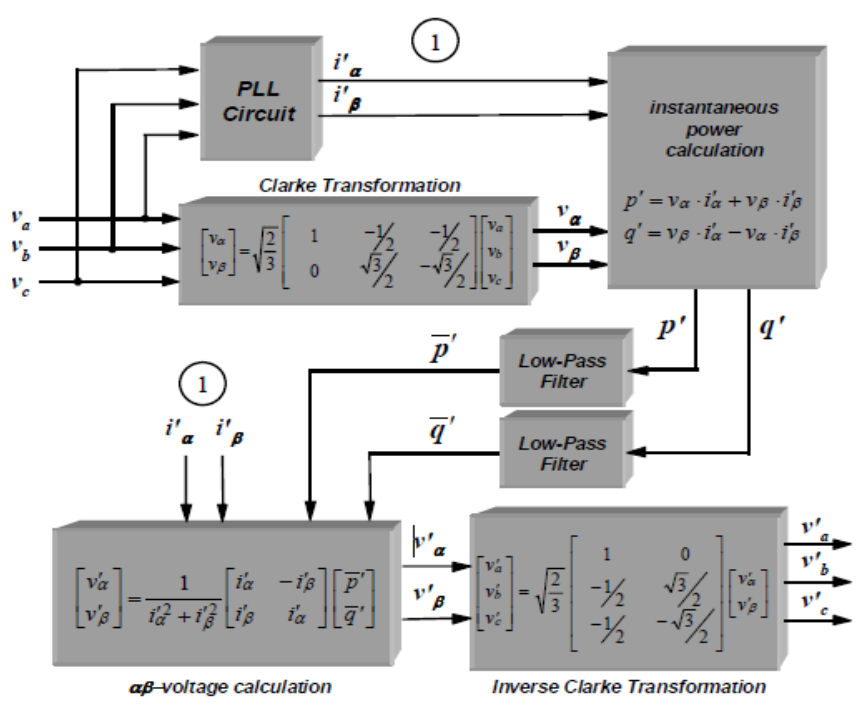

Fig.7. Control block diagram for fundamental positive-sequence voltage detector.

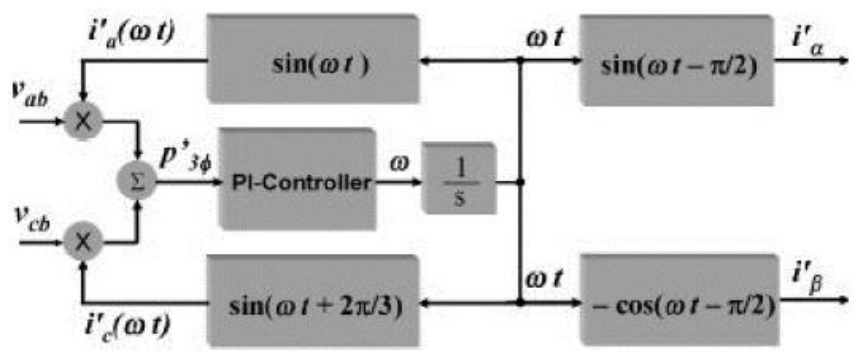

Fig.8. Control block diagram for the PLL circuit.

\section{Generalized Fryze Current Control Strategy}

This control strategy for of harmonic compensation is one of the most important and effective strategy among other control strategy where it compensates more harmonics than other control strategy. The current compensated by means of this control strategy presents a minimum RMS value to draw the same three-phase average active power from the source as the original load current and this reduces losses in the transmission system. The advantage of this generalized Fryze current control is the reduction of calculation effort, since it handles directly with the abc phase voltages and line currents which makes this control strategy is very simple. Fig. 9 shows the control algorithm for a Generalized Fryze Current Control Strategy. [7],[13].

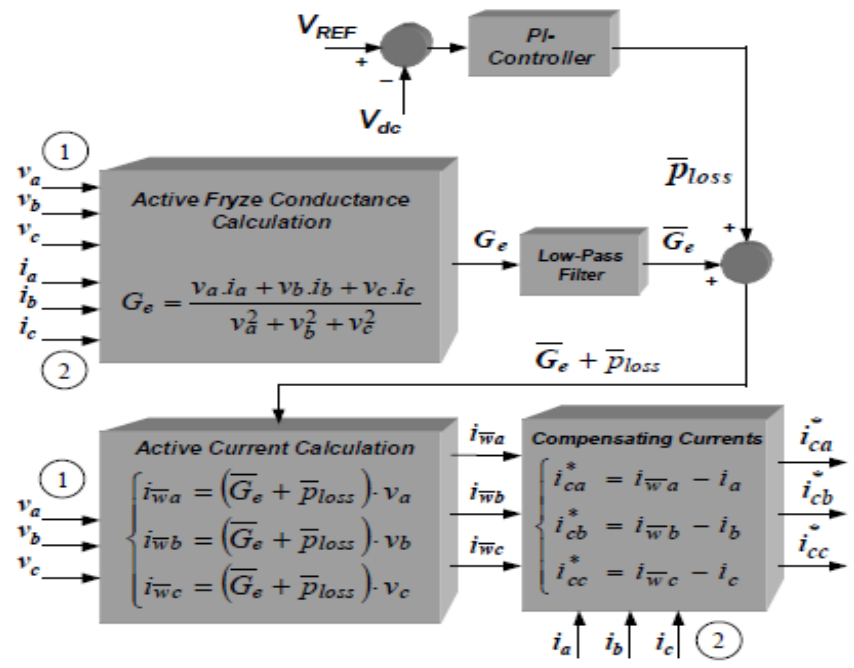

Fig.9. Control block diagram for Generalized Fryze Current Control Strategy.

\section{Sinusoidal Fryze Current Control Strategy}

This control strategy is a combination of that two strategies mentioned before, where it tries to keep the compensation flexibility as in the first method and reduces computation efforts as in the second method and it has the same kernel and based on a control strategy that is known as the Generalized Fryze Current,This control strategy is associated with a fundamental positive-sequence voltage detector to avoid the critical drawback of the Generalized Fryze Currents when the system voltages have unbalances and/or distortions but it differs from that proposed in the second method for finding of the fundamental, positivesequence, voltage component. This control strategy is created and extended to power electronics applications and used to solve a problem of finding the minimum (active) current component that transports the same energy of a generic three-phase load current. The difference between the generic load current and that minimized current comprises all harmonic current components that does not contribute to the transport of energy between the power supply and the generic load. The results for this control strategy cannot guarantee sinusoidal and balanced compensated currents if the system voltage at the PCC is distorted and/or unbalanced but it can guarantee compensated currents that are proportional to the system voltage and have the same waveforms, Also this control strategy is works directly without needing for any transformation, where this elimination of the Clarke transformation reduced calculation and requires less computation efforts which making this strategy simple comparing with the previous methods [9][10],[13],[14].

The combination between the proposed positive-sequence voltage detectors, together with the Generalized Fryze Currents control strategy constitutes a new control strategy Which known as the Sinusoidal Fryze Currents control strategy, where Fig. 10 shows the complete functional block diagram of the SAPF controller based on Sinusoidal Fryze Current Control Strategy which consists from three main parts, The first part is the proposed positive-sequence voltage detector shown in Fig. 11 which implemented with the addition of a synchronizing (PLL) circuit that tracks continuously the fundamental frequency of the system voltage and allowed proper operation under distorted and unbalanced system voltage as shown in Fig. 12,[15],[16].

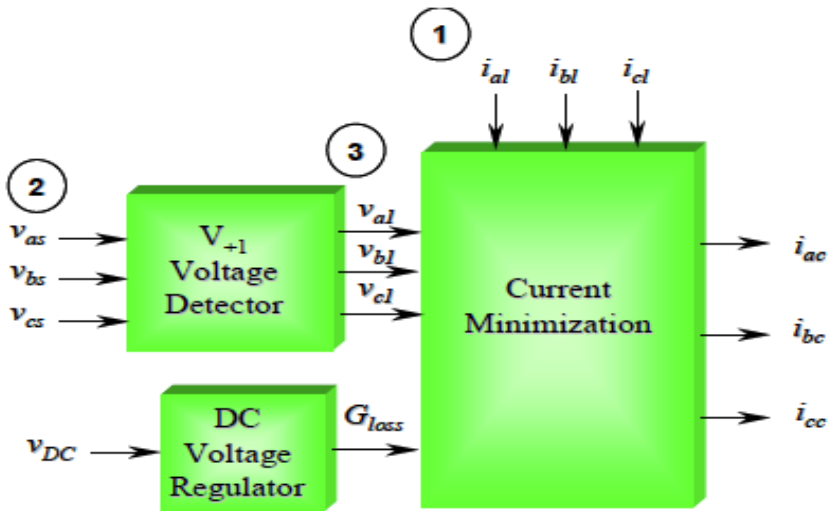

Fig.10. Functional Control block diagram for Sinusoidal Fryze Current Control Strategy. 


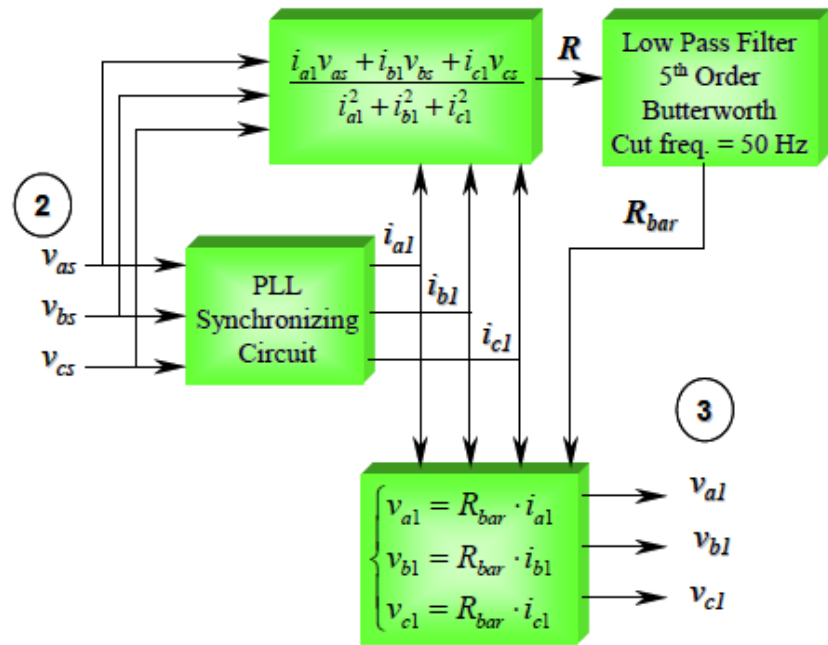

Fig.11. Control block diagram for Positive Sequence $\left(V_{+1}\right)$ Voltage Detector.

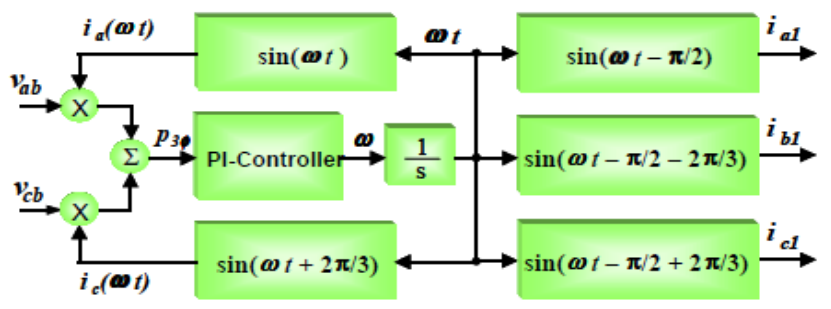

Fig. 12. The Synchronizing (PLL) Circuit.

The second part in the functional control diagram is "Current Minimization" which detailed in the Fig. 13 and it implemented to determine the instantaneous compensating reference currents, where SAPF compensates the difference between this calculated active currents and the actual measured load currents which synthesized by the converter of the shunt active power filter [15].

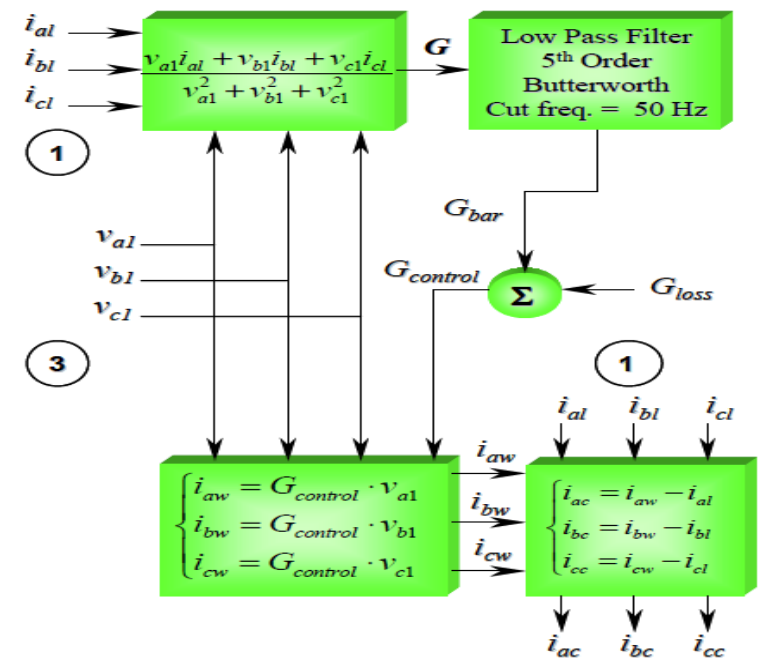

Fig.13. The Current Minimization control algorithm.

The third and last part in the control diagram is the dc voltage regulator shown in Fig. 14 and it used to generate a control signal that forces the SAPF to draw additional active current from the network, to compensate for losses in the power circuit of the SAPF. Also, it corrects dc voltage variations caused by abnormal operation and transient compensation errors [15],[16].

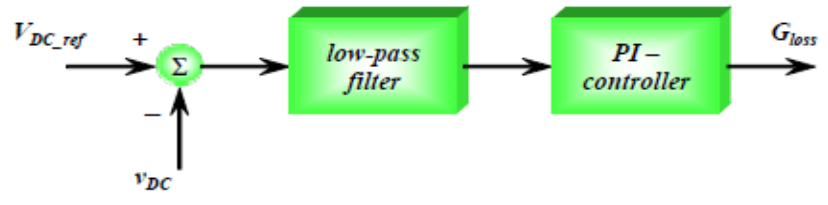

Fig.14. The DC voltage regulator.

Finally, based on this proposed controller, it is possible to guarantee that the compensated currents drawn from the network are always sinusoidal, balanced and in phase with the positive sequence system voltages and this function introduces a great enhancement done at the "Generalized Fryze Currents" by applying of Sinusoidal Fryze Current Control Strategy [15],[16].

\section{PROPOSED SYSTEM PARAMETERS}

Where the control strategy is the heart for SAPF ,therefor to study the dynamic performance for the previous three control strategies under distorted/non-distorted supply voltage the simulating system is very important, where the proposed system shown in Fig. 15 is composed mainly of AC utility grid (three phase distribution voltage source) connected to a nonlinear load through a transmission line (feeder) with a certain length and a conventional voltage source converter (VSC) acting as shunt active power filter SAPF which exposed to the hysteresis current controller technique (HCCT). The parameters of these elements which connected together at the PCC are given in Table I.

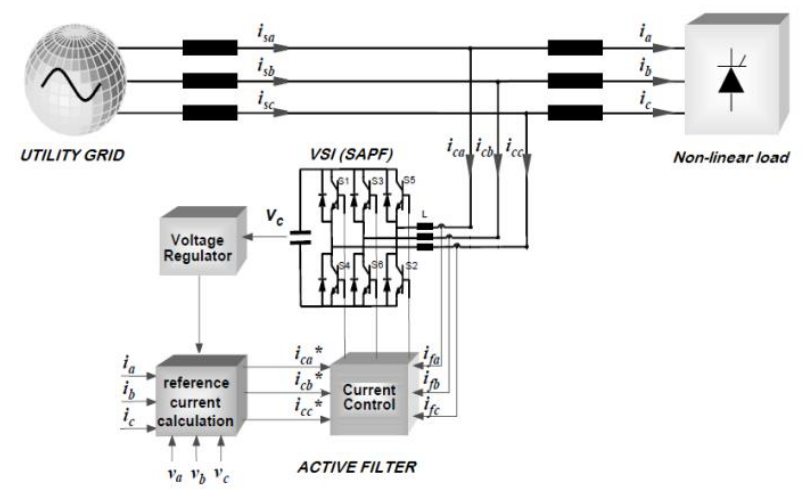

Fig.15. proposed simulation system.

TABLE I: PROPOSED SYSTEM PARAMETERS

\begin{tabular}{clll}
\hline \hline Element & Parameter & Value & Symbol \\
\hline & & & \\
& Line-to-line voltage & $380 \mathrm{~V}$ & $\mathrm{~V}_{\mathrm{S}}$ \\
& Line frequency & $50 \mathrm{~Hz}$ & $\mathrm{~F}_{\mathrm{S}}$ \\
AC Utility & Line resistance & $5 \Omega$ & $\mathrm{R}_{\mathrm{S}}$ \\
Grid & Line inductance & $2 \mathrm{mH}$ & $\mathrm{L}_{\mathrm{S}}$ \\
& Feeder resistance & $0.115 \Omega / \mathrm{km}$ & $\mathrm{R}_{\mathrm{F}}$ \\
& Feeder inductance & $1.05 \mathrm{mH} / \mathrm{km}$ & $\mathrm{L}_{\mathrm{F}}$ \\
& Feeder capacitance & $11.33 \mathrm{nF} / \mathrm{km}$ & $\mathrm{C}_{\mathrm{F}}$ \\
& Feeder length & $1.5 \mathrm{Km}$ & $\mathrm{Km}$ \\
Non-linear & DC inductance & $10 \Omega$ & \\
load & DC resistance & $20 \mathrm{mH}$ & $\mathrm{R}_{\mathrm{dc}}$ \\
Shunt & & & $\mathrm{L}_{\mathrm{dc}}$ \\
Active & Interfacing resistance & $1 \Omega$ & \\
Power & Interfacing inductance & $3 \mathrm{mH}$ & $\mathrm{R}_{\mathrm{AF}}$ \\
Filter & DC link capacitor & $10 \mathrm{mF}$ & $\mathrm{L}_{\mathrm{AF}}$ \\
(SAPF) & Capacitor initial voltage & 1000 & $\mathrm{C}_{\mathrm{dc}}$ \\
& & & $\mathrm{V}_{\mathrm{dc}}$ \\
\end{tabular}




\section{IV.SIMULATION RESULTS}

The purpose of the simulation is to show the effectiveness for different current controller of the shunt active power (SAPF) filter in reducing the harmonic pollution produced on the load side under sinusoidal (non-distorted) and nonsinusoidal (distorted) utility voltages conditions, where MATLAB/SIMULINK is developed as a simulation tool to implement the proposed SAPF and study its performance for harmonic current elimination and reactive power compensation at PCC in power distribution system. The proposed scheme is first simulated without filter to find out the total harmonic distortion (THD) for the supply current and its power factor, and then it is simulated with the SAPF and comparing between results obtained from different current controller methods. The results which obtained when system simulated without SAPF is shown in Fig. 16 and implement the THD for supply current and its spectrum and power factor when in two cases when supply voltage is nondistorted and distorted.

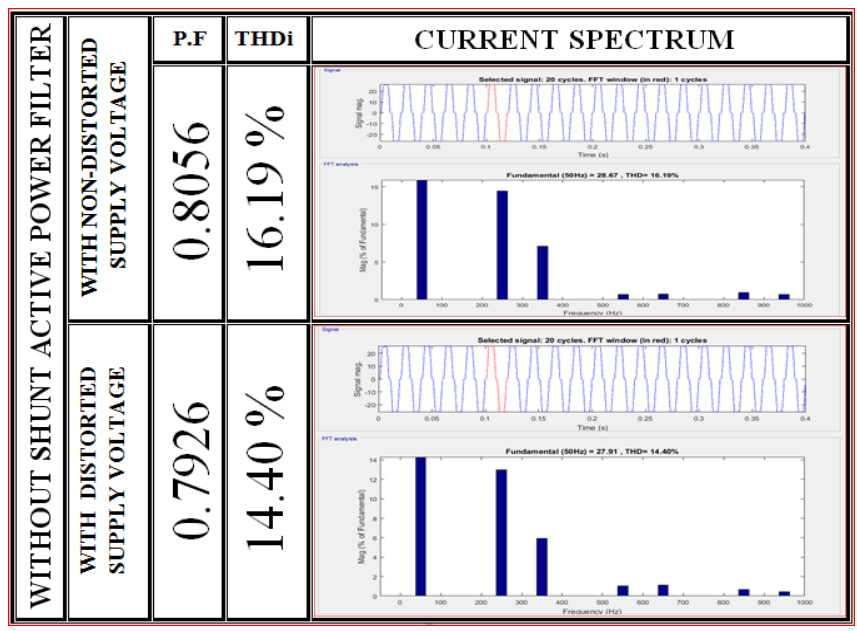

Fig.16. THD and P.F values with supply voltage distorted and non-distorted conditions without SAPF

The waveforms and spectrums for sinusoidal and nonsinusoidal supply voltage are shown in Fig. 17, where the THD for sinusoidal voltage is $0.02 \%$ and the THD for non sinusoidal voltage is $35.61 \%$ which measured on the end (bus) of the feeder with length is $1.5 \mathrm{~km}$ from the grid.

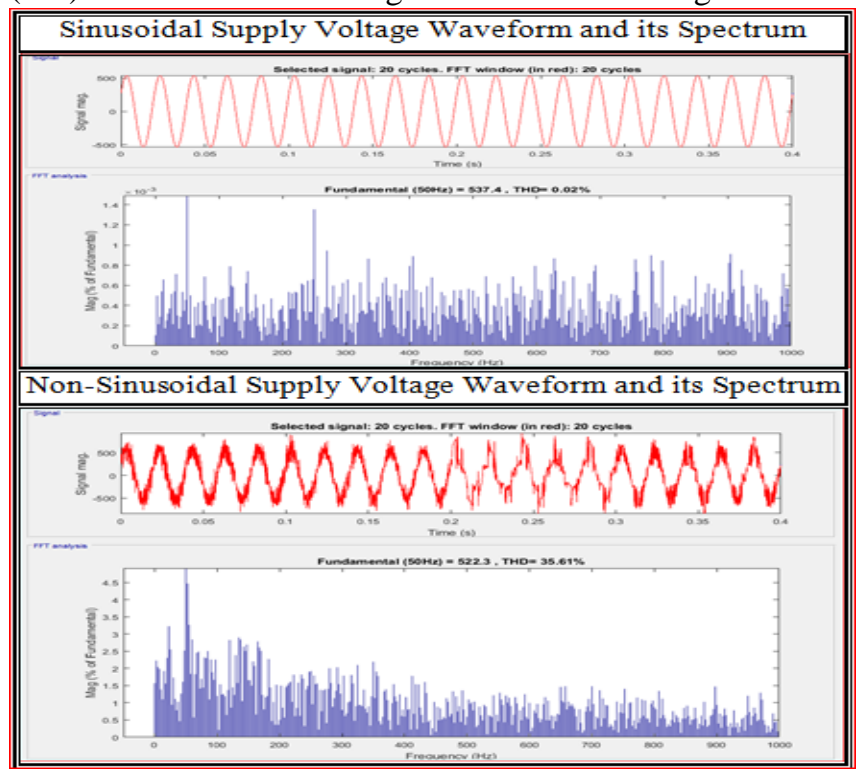

Fig.17. THD for sinusoidal and non-sinusoidal utility voltage.
The proposed system with SAPF is simulated with previous four current control strategies which mentioned above and taken the harmonic spectrums for supply current under sinusoidal and non-sinusoidal utility voltages conditions which observed and mentioned as shown in Fig. 18 and 19, also the waveforms for utility (supply) current, non-linear load current, and filter current under sinusoidal and non-sinusoidal utility these conditions are shown in Fig. 20. Finally, Table II, summarizes all results for THD and P.F under different control strategies and supply voltage conditions where constant instantaneous power control strategy are simulated from 0.0 to 0.1 and sinusoidal current control strategy are applied after that from 0.1 to 0.2 and then applied generalized fryze current control strategy from 0.2 to 0.3 and finally applied sinusoidal fryze current control strategy from 0.3 to 0.4 with represent the total simulation time.

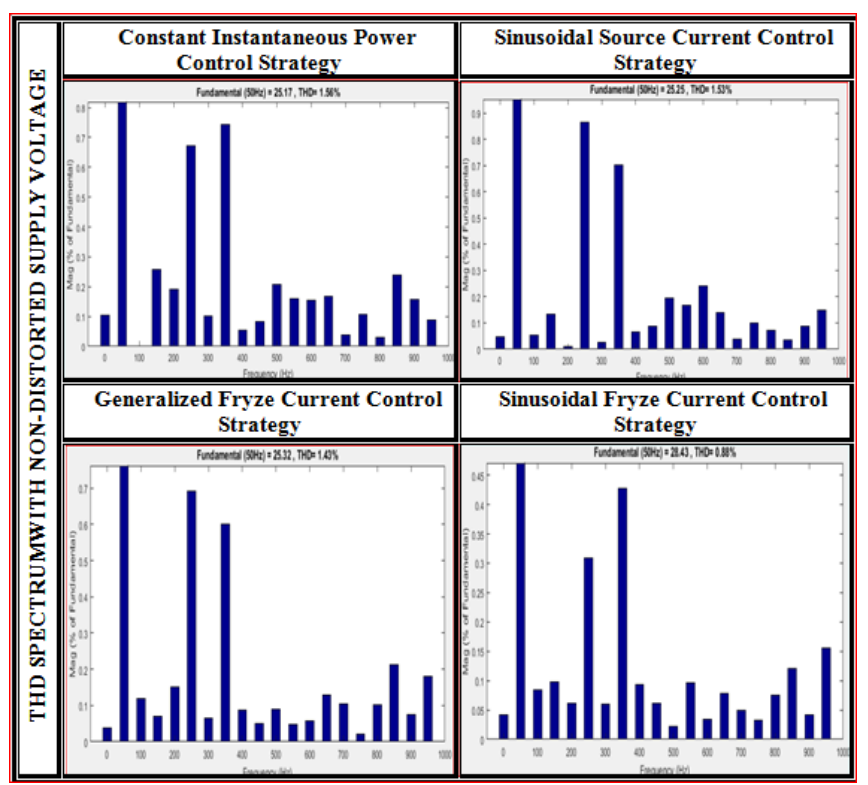

Fig.18.THD Spectrum for supply current with four control strategies under sinusoidal supply voltage

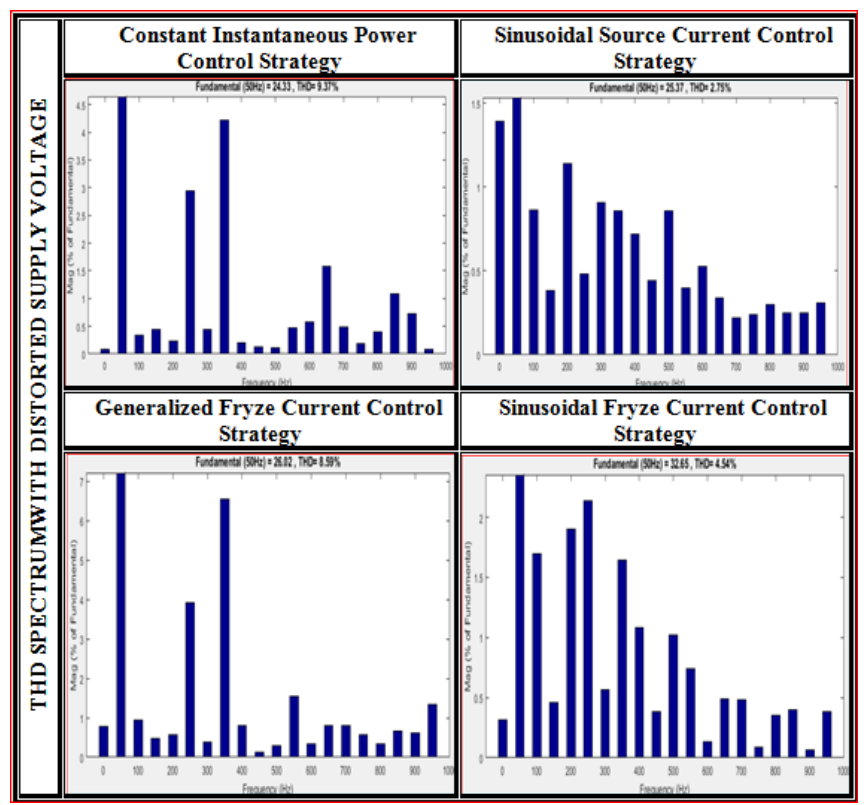

Fig.19.THD Spectrum for supply current with four control strategies under non- sinusoidal supply voltage 


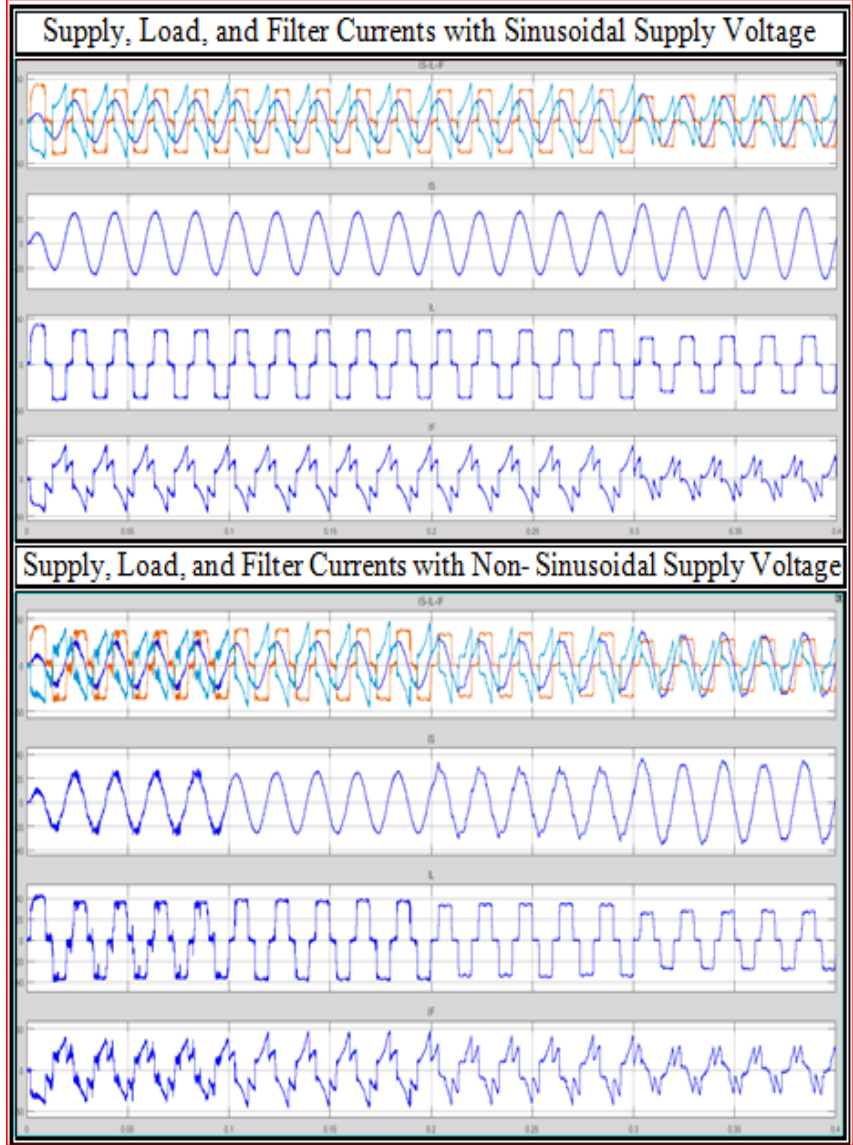

Fig.20. Supply, load, and filter currents under different supply voltage conditions with SAPF.

TABLE II: SiMULATION RESULTS

\begin{tabular}{|c|c|c|c|}
\hline Case & Control theory & P.F & THDi (\%) \\
\hline \multirow{4}{*}{$\begin{array}{l}\text { With Non- } \\
\text { distorted } \\
\text { supply } \\
\text { voltage } \\
\text { and SAPF }\end{array}$} & $\begin{array}{l}\text { Constant Instantaneous } \\
\text { Power Control Strategy }\end{array}$ & 1 & $1.56 \%$ \\
\hline & $\begin{array}{c}\text { Sinusoidal Source Current } \\
\text { Control Strategy } \\
\text { Line inductance }\end{array}$ & 1 & $1.53 \%$ \\
\hline & $\begin{array}{c}\text { Generalized Fryze Current } \\
\text { Control Strategy }\end{array}$ & 1 & $1.43 \%$ \\
\hline & $\begin{array}{c}\text { Sinusoidal Fryze Current } \\
\text { Control Strategy }\end{array}$ & 0.9644 & $0.88 \%$ \\
\hline \multirow{4}{*}{$\begin{array}{c}\text { With } \\
\text { distorted } \\
\text { supply } \\
\text { voltage } \\
\text { and SAPF }\end{array}$} & $\begin{array}{l}\text { Constant Instantaneous } \\
\text { Power Control Strategy }\end{array}$ & 0.9945 & $9.37 \%$ \\
\hline & $\begin{array}{c}\text { Sinusoidal Source Current } \\
\text { Control Strategy } \\
\text { Line inductance }\end{array}$ & 1 & $2.75 \%$ \\
\hline & $\begin{array}{c}\text { Generalized Fryze Current } \\
\text { Control Strategy }\end{array}$ & 0.9825 & $8.59 \%$ \\
\hline & $\begin{array}{c}\text { Sinusoidal Fryze Current } \\
\text { Control Strategy }\end{array}$ & 0.9538 & $4.54 \%$ \\
\hline
\end{tabular}

\section{CONCLUSION}

From simulation results taken under different current control strategies, it observed that the supply voltage conditions represent a very important role and all proposed control theories are affected by this condition and performances for all controllers are different from each other when supply voltage is non-sinusoidal. From view point of power quality, it important to introduce a control algorithm making the function of supply current harmonic elimination and also compensate the system power factor with an acceptable value for THD compatible with the power quality recommended international standards under different supply voltage conditions. With sinusoidal supply voltage all proposed control theories give an acceptable values for THD and P.F, also with non-sinusoidal supply voltage the control theories give an acceptable values for power factor correction and the best value is unity power factor which taken with sinusoidal current control strategy but with THD all controllers based on using of fundamental positive sequence detector algorithm which deal with supply voltage distortion give an acceptable values within the suitable THD range less than $5 \%$ where with sinusoidal fryze current control strategy the THD is $4.54 \%$,but also the sinusoidal current control strategy achieved the least values for THD with a value of $2.75 \%$, therefore the sinusoidal current control strategy introduce the best control performance with distorted and non-distorted supply voltage conditions.

\section{ACKNOWLEDGMENT}

We would like to thank all professors of electrical power in electrical engineering department, faculty of engineering, Al-Azhar University for the technical assistance they gave to us during the work of preparing this paper.

\section{REFERENCES}

[1] Rakhee Panigrahi, "Development of Robust Control Schemes with New Estimation Algorithms for Shunt Active Power Filter," Ph.D.dissertation, Dept. Elect. Eng., National Institute of Technology Rourkela., Roll No:510EE111, Odisha, India, 2015

[2] Gaber EL-Saady , EL-Noby A. Ibrahim, and Mohamed Amin, "DESIGN AND SIMULATION OF SHUNT ACTIVE POWER FILTER FOR ASSIUT CEMENT COMPANY DC MOTOR DRIVE ,'Journal of Engineering Sciences, Assiut University, Faculty of Engineering, Vol. 41, No. 6, pp. 2244 - 2259,November, 2013.

[3] S.K.EL-Sayed, A.M.AttiyaSoliman, "POWER QUALITY IMPROVEMENT FOR DISTRIBUTION NETWORK BY DESIGN OF TWO CONTROL STRATEGIES FOR ACTIVE POWER FILTER," International Journal of Engineering and Advanced Technology Studies., Vol.3, No.3, pp.1-22, October 2015.

[4] Sneha Sanjay Nirmale, Sangeeta Mahaddalkar, "Review of Control Strategies for Active Power Filters ,"National Conference on Advances in Electrical Engineering (NCAEE), NMAM Institute of Technology, Nitte,india,Vol. 5, Special Issue 2, April 2017.

[5] P.M.Balasubramaniam, and G. Gurusamy, "Evaluation and Implementation of a Shunt Active Power Filter under balanced Source Voltages," Journal of Engineering Science and Technology, Vol. 5, No. 2, pp. 35 - 41, September 2012.

[6] A .M .Attiya Soliman, T.A.Kandil, M.A.Mehanna, S.K.EL-Sayed "Mitigation of the Effect of HVDC System on Power System Quality at Distribution Level," International Journal of Engineering and Innovative Technology (IJEIT) Volume 4, Issue 6, December 2014.

[7] R. Kazemzadeh1, E. Najafi Aghdam, M. Fallah, Y. Hashemi "Performance Scrutiny of Two Control Schemes Based on DSM and HB in Active Power Filter," Journal of Operation and Automation in Power Engineering, Vol. 2, No.2, pp.103-112, Jul 2014.

[8] Alexandru Bitoleanu, Mihaela Popescu, Vlad Suru“High Performance Shunt Active Power Filter: Design Consideration and Experimental Evaluation," ANALELE UNIVERSITĂȚII,"EFTIMIE MURGU" REŞIŢA ,ANUL XXI, NR. 3, ISSN 1453 - 7397, 2014.

[9] Pratik J Kunvarani Alpesh M Upadhyay, "A Control Strategy for Shunt Active Filter," International Journal for Scientific Research \& Development (IJSRD), Vol. 2, Issue 03, 2014.

[10] M. Aredes, Luís F. C. Monteiro, "A Control Strategy for Shunt Active Filter," 10th ICHQP - IEEE/PES 10th Int. Conf. on Harmonics and Quality of Power, Rio de Janeiro, Brazil, vol.1, pp.472-477 October 2002. 
[11] Hirofumi Akagi,Edson Hirokazu Watanabe, Mauricio Aredes, INSTANTANEOUS POWER THEORY AND APPLICATIONS TO POWER CONDITIONING,1st ed. HOBOKEN,NEW JERSEY,USA: A JOHN WILEY\& SONS,INC ,2007. ch. 4, pp.120-231.

[12] Maur'icio Aredes J"urgen H"afner, and Klemens Heumann, "ThreePhase Four-Wire Shunt Active Filter Control Strategies," IEEE TRANSACTIONS ON POWER ELECTRONICS, VOL. 12, NO. 2, MARCH 1997.

[13] Luís F. C. Monteiro, M. Aredes, "A Comparative Analysis Among Different Control Strategies for Shunt Active Filters," Proc. (CDROM) of the $\mathrm{V}$ INDUSCON - Conferência de Aplicações Industriais, Salvador, Brazil, pp.345-350, July 2002.

[14] NimaZabihi and Rupert Gouws, " Analysing Two Control Methods of Shunt Active Filters for Unbalanced Load," International Journal of Research in Engineering and Applied Sciences(IJREAS), Vol. 02, Issue 02, July 2014.

[15] M. Aredes, Luís F. C. Monteiro, Jaime M. Miguel, "Control Strategies for Series and Shunt Active Filters," Proc. (CDROM) of the 2003 IEEE Bologna Power Tech - IEEE Bologna Power Tech Conference, Bologna, Italy, vol.1, pp.1-6, July 2003.

[16] Luís F. C. Monteiro, M. Aredes, João A. M. Neto, "A Control Strategy for Unified Power Quality Conditioner," Proc. (CDROM) of the ISIE'2003 - International Symposium on Industrial Electronics, Rio de Janeiro, Brazil, vol.1, pp.1-6, June 2003.

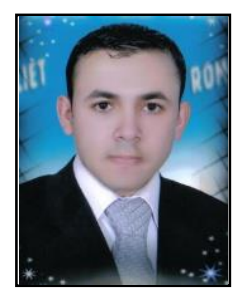

Eng. A. M. Attiya Soliman is currently working as assistant lecturer in the department of electrical power and machines, faculty of engineering, AlAzhar University, Egypt. He has been interested in different fields like power electronics applications, high voltage direct current (HVDC) system, integration of Renewable energy sources like photovoltaic and wind system in electrical distribution networks, and also working on different control strategies solving electrical power quality problems like harmonics and poor power factor and he has published 2 research papers related these points through an international scientific engineering journals.

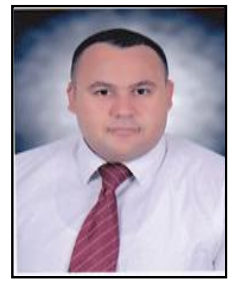

Dr. S. K. EL-Sayed is currently working as assistant lecturer in the department of electrical power and machines, faculty of engineering, AlAzhar University, Egypt. He has been interested in different fields like electrical power system analysis, FACTS, and power system stability, power system quality, renewable energy systems applications like design for solar energy system, protection of electrical power system, design for electrical distribution systems and he has published about 15 research papers related these fields through an international scientific engineering journals.

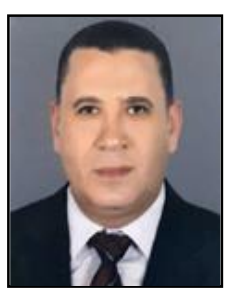

Prof.Dr. M. A. Mehanna is currently working as assistant professor in the department of electrical power and machines, faculty of engineering, AlAzhar University, Egypt. He has been interested in different fields like configuration of electrical distribution network, numerical analysis methods for electrical power system, high voltage technologies, and assessment of power system stability, integration of distributed generation technologies with power system network, protection and earth systems and he has published about 25 research papers related these fields through an international scientific engineering journals. 